\title{
O CAMINHO PARA O CONCEITO DE SUSTENTABILIDADE
}

Marcos Leite Garcia

Doutor em Direito. Doutorado realizado no Instituto de Direitos Humanos da Universidade Complutense de Madrid. Realizou estágio de pós-doutorado na Universidade Federal de Santa Catarina. Professor permanente do Programa Stricto Sensu em Ciência Jurídica da Universidade do Vale do Itajaí - Santa Catarina (UNIVALI), Cursos de Mestrado e Doutorado. Membro vitalício da Academia Catarinense de Letras Jurídicas - ACALEJ. Autor de diversos artigos e capítulos de livros sobre os tema dos direitos fundamentais, constitucionalismo democrático e sustentabilidade.E.mail: mleitegarcia@terra.com.br

\section{Dirajaia Esse Pruner}

Doutoranda em Direito pelo Programa Stricto Sensu em Ciência Jurídica da Universidade do Vale do Itajaí - Santa Catarina (UNIVALI). Mestre em Ciência Jurídica pela UNIVALI (2005), Pós Graduada em Nível de Aperfeiçoamento pela Escola da Magistratura Trabalhista e Pós-Graduação em Direito do Trabalho da 12. Região (2001). Graduada em Direito pela Universidade do Vale do Itajaí (2000). É professora e responsável pelo Núcleo de Prática Jurídica da Universidade do Vale do Itajaí, Unidade Kobrasol. E-mail:dirajaia@univali.br

\section{Resumo}

O presente artigo tem como objetivo apresentar um estudo acerca do conceito de sustentabilidade tendo como objetivo geral demonstrar a diferença conceitual entre as expressôes desenvolvimento sustentável e sustentabilidade. Para a melhor compreensão do tema, inicialmente, será realizado um breve relato histórico sobre o surgimento da expressão desenvolvimento sustentável, para posteriormente ser apresentado o seu conceito. Em seguida serão abordados alguns eventos internacionais que contribuíram para a construção do conceito de sustentabilidade e, por fim, abordar-se-á o seu conceito.

\section{Palavras-chave}

Desenvolvimento sustentável; Sustentabilidade; Conceito.

\section{Resumen}

El presente artículo pretende presentar un estudio acerca del concepto de sostenibilidad y tiene como objetivo general demostrar la diferencia conceptual entre los términos 
desarrollo sostenible y sostenibilidad. Para una mejor comprensión del tema, en principio, será realizada una breve reseña histórica sobre la expresión desarrollo sostenible, para posteriormente ser presentado su concepto. En seguida abordase algunos eventos internacionales que contribuyeron para la construcción del concepto de sostenibilidad y, por último, ser presentado su concepto.

\section{Palabras clave}

Desarrollo sostenible; Sostenibilidad; Concepto.

\section{Introdução}

O presente artigo busca apresentar um estudo acerca do conceito de sustentabilidade. No entanto, abordar o tema sustentabilidade sem falar de desenvolvimento sustentável é quase impossível tendo em vista que, em vários momentos, as expressóes são utilizadas com o mesmo significado.

Assim, é importante deixar claro que desenvolvimento sustentável e sustentabilidade são conceitos diferentes. Atualmente, a utilização de ambas as expressões sem o cuidado e o aporte teórico necessário, vem causando verdadeira confusão e até mesmo uma certa repulsa sobre tudo que diz respeito a sustentabilidade. Desta forma, a diferenciaçáo destes dois conceitos torna-se de suma importância para que os mesmos não sejam desacreditados.

Para a melhor compreensão do tema, inicialmente, será realizado um breve relato histórico sobre o surgimento da expressão desenvolvimento sustentável, para, posteriormente, ser apresentado o seu conceito.

Em seguida serão abordados alguns eventos internacionais que contribuíram para a construção do conceito de sustentabilidade e, por fim, abordar-se-á o seu conceito.

É certo que, evidentemente, o conceito de sustentabilidade ainda está sendo construído. O tema, apesar de ser discutido há tempos, ganhou protagonismo apenas nos últimos anos e, portanto, pode ser considerado novo. Há apenas poucas décadas é que estudiosos e cientistas dedicam-se a estudar e construir uma ideia única sobre sustentabilidade, mas, certamente, a discussão está longe de ter um ponto final. E, quem sabe, não terá o tal ponto final, pois o conceito de sustentabilidade parece um daqueles conceitos abertos que são, a todo tempo, melhorados, reconstruídos, incrementados. Cabe a comunidade científica, na qual me incluo como doutoranda, contribuir para o esclarecimento e para a construção contínua deste conceito tão importante para a sobrevivência da espécie humana.

\section{Origem e Conceito da Expressão Desenvolvimento Sustentável}

No dias de hoje, os debates sobre o crescimento econômico sempre vêm acompanhados da utilização da expressão desenvolvimento sustentável. Para seu completo 
entendimento é necessária um breve histórico abordando os principais eventos e discussões ambientais travados ao longo dos anos.

Com relação a destruição ambiental e a tomada de consciência sobre ela, cabe destacar que, mesmo tendo os movimentos de proteção ao meio ambiente iniciado no pós guerra, há relatos muito antigos sobre críticas à exploração ambiental. Platão questionava o corte de árvores para utilização como lenha e já se criticava a redução das florestas europeias quando da construção dos navios para as grandes navegaçóes. ${ }^{1}$

No entanto, até bem depois da Revolução Industrial, havia pouco alarme sobre a degradação ambiental, o que só passou a ocorrer por meio do progresso científico. Quando os cientistas começaram a divulgar estudos sobre a estrutura da natureza as pessoas começaram a perceber como ela poderia ser, e estava sendo, afetada pela ação humana. Os primeiros movimentos de proteção ao meio ambiente começaram a surgir, tanto nos Estados Unidos da América (EUA) como na Grã-Bretanha, a partir da segunda metade do século XIX, mas, a preocupação da sociedade com estes temas ainda era incipiente. ${ }^{2}$

No Brasil, por volta da década de 1930, discutia-se a questão da proteção do patrimônio natural, principalmente do patrimônio vegetal, tendo em vista que a sociedade se organizava em torno do extrativismo e da agricultura. Em 1934 foi elaborado o primeiro Código Florestal e, em 1937, criado o primeiro parque nacional brasileiro, o Itatiaia. ${ }^{3}$

Internacionalmente, o período pós Primeira e Segunda Guerras Mundiais foi marcado por grandes discussóes internacionais a respeito da cooperaçáo entre as naçóes para a solução dos problemas da época. A preocupação daquele tempo era com o crescimento excessivo da população, com a conservação dos recursos naturais e até com a criação de uma organização internacional capaz de cuidar da proteção da natureza. ${ }^{4}$

A década de 1950, especialmente para os Estados Unidos da América, foi um período de muito progresso. Houve crescimento econômico constante, empregos em abundância, aumento do consumo, enfim, a sociedade americana passava por anos dourados. No entanto, os jovens cultos e bem educados de todas as naçóes industrializadas do mundo, membros de uma classe média para a qual não faltava nada, percebiam os problemas do seu entorno. Havia a guerra fria, a ameaça nuclear, ameaça de novas guerras, e as injustiças sociais cometidas pelo racismo. Todos estes fatores nutriam nestes jovens um sentimento de insatisfação que só fazia crescer. ${ }^{5}$

1 McCORMICK, John. Rumo ao paraíso: A história dos movimentos ambientalistas. Rio de Janeiro: Dumará Distribuidora de Publicaçôes, 1992. p.15.

2 Ibid., p.15.

3 ALMEIDA, Fernando. O bom negócio da sustentabilidade. Rio de Janeiro: Nova Fronteira, 2002. p.14.

4 McCORMICK, op. cit., p.43.

5 Ibid. p. 65-71. 
Já no Brasil a década de 1950 teve como destaque o governo de Juscelino Kubitscheck, o qual possuía uma política econômica audaciosa cujo objetivo era fazer o país crescer 50 anos em 5 anos. Foram tempos de grande industrializaçáo e junto com ela veio o aumento da poluição. Em 1958, reagindo a toda a degradação ambiental que a industrialização havia produzido, foi criada a primeira organização ambientalista brasileira, a Fundação Brasileira para a Conservação da Natureza - FBCN. Os efeitos desta criação foram sentidos ao final da década de 1950 e no início da década de 1960 com a criação de vários parques nacionais. ${ }^{6}$

A década de 1960, nos EUA, começa com um grande lançamento literário, Primavera Silenciosa, de Rachel Louise Carson ${ }^{7}$, que denunciava danos ambientais causados pela utilização indiscriminada de pesticidas. Esta obra teve grande impacto na opiniáo pública mundial pois auxiliou na compreensão de que os resíduos químicos da atividade industrial destas últimas décadas estavam contaminando animais, solo, ar, e a água de todo o planeta. ${ }^{8}$

Mundialmente, entre os anos de 1966 e 1973 vários desastres ambientais ocorreram e foram amplamente divulgados na mídia. Em 1966 houve o tombamento de uma pilha de resíduos de uma mina de Alberfan, no sul do país de Gales, que matou 144 pessoas, dentre elas 116 crianças. Em 1967 o petroleiro Torrey Canyon se acidenta ao bater em um rocha no litoral da Inglaterra e espalha 117 mil toneladas de petróleo no mar. Em 1969 houve um jorro acidental de petróleo em uma plataforma no litoral de Santa Bárbara nos EUA. Entre 1961 e 1973 várias indústrias japonesas foram condenadas ao pagamento de indenizaçóes por terem poluído rios e outras águas com seus dejetos industriais causando doenças à população. ${ }^{9}$

Em todos estes desastres a população, além de testemunhar as mortes e as doenças por eles provocadas, assistia também ao enorme gasto público empreendido na tentativa de conter os danos ambientais.

Todos este fatores, junto com tantas outras manifestaçôes ocorridas na década de 1960, como o feminismo, o início dos direitos do consumidor, o movimento hippie (que era anticonsumismo e defendia a harmonia do ser humano com a natureza), as manifestaçôes pelos direitos civis e as manifestaçôes anti-guerra nos EUA e a resistência de uma nova geração aos valores pré-estabelecidos na Europa, fez surgir a consciência do protesto e do quanto ele poderia modificar e transformar as situaçóes problemáticas. ${ }^{10}$

6 ALMEIDA, op. cit., p.14.

7 Veja-se a edição brasileira: CARSON, Rachel. Primavera Silenciosa. 1 ed. São Paulo: Gaia, 2010.

8 LAGO, André Aranha Corrêa do. Estocolmo, Rio, Joanesburgo: o Brasile as três conferências ambientais das Naçôes Unidas. Brasília: Instituto Rio Branco, 2006. p.28.

9 McCORMICK, op. cit., p.71-73.

10 ALMEIDA, op. cit., p.15. 
E assim, em um "tempo em que a palavra de ordem era contestar, a defesa da natureza logo se revelaria uma das poucas bandeiras capazes de juntar seguidores que, de outra forma, seriam totalmente inconciliáveis". ${ }^{11}$

Portanto, na década de 1960, inúmeros foram os protestos contra a degradação ambiental com repercussão global e múltiplos foram os estudos que surgiram sobre o futuro catastrófico da humanidade se a postura com relação ao meio ambiente não fosse modificada. $^{12}$

A década acima citada foi marcada pelo surgimento de uma nova consciência de proteção ambiental, um novo ambientalismo que ia além da conservação dos recursos naturais e da preocupação com o crescimento populacional, preocupava-se com a sobrevivência da raça humana. ${ }^{13}$

Em 1968, movido por estas preocupaçóes globais, o industrial italiano Aurélio Peccei, financiado por empresas como a FIAT e a Volkswagen, criou o Clube de Roma. Tratava-se de uma reunião de economistas, cientistas, educadores, industriais e membros de instituiçóes públicas de países desenvolvidos, preocupados com os rumos do futuro mundial..$^{14}$

O objetivo do Clube era incentivar a compreensão dos problemas mundiais, principalmente o ambiental, com base no estudo de todos os seus componentes e de como eles se interligavam. A proposta era que fosse feita uma análise econômica, política, natural e social demonstrando como todas estas questóes eram interligadas no sistema global e que só a compreensão de sua totalidade poderia levar a solução dos referidos problemas. ${ }^{15}$

É chegada a década de 1970 e a crise ambiental já não é mais silenciosa, era do conhecimento de todos. Estudos científicos demonstravam o quanto a raça humana estava ameaçada pela escassez de recursos e pela poluição do meio ambiente pelos dejetos industriais. Surgiram os primeiros debates sobre os limites do crescimento, principalmente no tocante ao crescimento populacional e a utilização dos recursos naturais. ${ }^{16}$

O Clube de Roma havia organizado uma equipe, liderada por Dennis Meadow e sua esposa Donella Meadows, que empreendeu um trabalho inovador para a época ao adotar um modelo proposto por Jay Forrester, Professor do Instituto de Tecnologia de Massachusetts, cuja sigla em inglês é MIT. A equipe utilizou um computador ultramoderno

11 Ibid., p.15.

12 Ibid., p.18.

13 McCORMICK, op. cit., p.76.

14 LAGO, André Aranha Corrêa do. Estocolmo, Rio, Joanesburgo: o Brasile e as três conferências ambientais das Naçōes Unidas. p.28.

15 McCORMICK, op. cit., p. 83.

16 Ibid., p.81. 
(naquela ocasião) para simular a evolução da economia mundial. Os resultados deste trabalho começaram a ser divulgados em uma Conferência Internacional do Clube, realizada no Rio de Janeiro, em 1971, mas sua publicação oficial ocorreu apenas em 1972, com o lançamento do livro intitulado: Os Limites do Crescimento, também conhecido como Relatório Meadows. ${ }^{17}$

Referido documento concluía que, o fundamento da crise ambiental estava no crescimento exponencial. Segundo o relatório, a natureza não é uma fonte inesgotável e o crescimento exponencial da indústria, da produção agrícola, da população mundial e dos níveis de poluição consumiria os recursos naturais, que cresciam em níveis lineares, até o colapso completo. Desta forma, a única solução vislumbrada à época era o crescimento zero. Assim, o livro sugeriu a redução de investimentos na indústria, na produção agrícola, redução da taxa de natalidade e até mesmo a transferência de riqueza dos países ricos para pobres (para que se pudesse criar um equilíbrio entre os países). Só desta forma, freando o crescimento, é que seria possível reestabelecer o equilíbrio entre o homem e a natureza. ${ }^{18}$

O supracitado livro recebeu muitas críticas, suas conclusóes foram atacadas em virtude da metodologia utilizada, de não terem feito diferença entre países desenvolvidos e subdesenvolvidos, de não terem feito distinção entre países do norte e do sul e entre regiōes rurais e industrializadas. No entanto, a maior contribuição do Clube de Roma com este relatório foi a de provocar a humanidade e colocar o assunto na rodas internacionais de discussão. ${ }^{19}$

Assim, a Organização das Naçôes Unidas - ONU resolveu realizar, em 1972, a Conferência de Estocolmo. Tal Conferência tinha como lema "Uma só Terra” e como objetivo o debate das relaçóes entre sociedade e meio ambiente. ${ }^{20}$

Nos preparativos para a referida conferência o Brasil se destacou por sua postura ativa no questionamento dos resultados apresentados no relatório Os Limites do Crescimento. Os brasileiros promoveram a reunião dos países em desenvolvimento em um bloco de peso que conseguiu ser ouvido nesta fase preparatória e durante toda a Conferência. Maurice Strong, Secretário Geral da Conferência de Estocolmo, foi trazido ao Brasil e ouviu "de seus anfitrióes veementes discursos sobre a impropriedade de se aplicar ao Hemisfério Sul, com suas peculiaridades geográficas e climáticas, os mesmos critérios antipoluição do Hemisfério Norte." 21

17 LAGO, op. cit., p.29.

18 McCORMICK, op. cit., p.97-89.

19 OLIVEIRA, José Antônio Pupim de. Empresas na sociedade: sustentabilidade e responsabilidade social. Rio de Janeiro:Elsevier, 2008, p.21-23.

20 Rafael Hurtado Rodero in ROBLEDO, Irene Saavedra (coord.). Introducción a la sostenibilidad y la RSC. La Coruña: Netbiblo, 2010. p.10.

21 ALMEIDA, op. cit., p.18. 
Quando a Conferência de Estocolmo começou notava-se a transformação da concepção a respeito dos assuntos que seriam ali tratados. Os ânimos já estavam preparados para a discussão dos problemas ambientais globais respeitando a perspectiva dos países menos desenvolvidos.

Referida conferência teve quatro resultados importantes. Primeiro ocorreu a mudança de foco nas questóes relativas ao meio ambiente, agora o debate era travado acerca das características do meio ambiente que afetavam a vida humana. Este foi o grande diferencial entre a reunião de Estocolmo e outras reuniôes internacionais: anteriormente tratavam o meio ambiente como um assunto dissociado da sobre vivência da raça humana e agora o viam como uma condição para que estava sobrevivência se perpetuasse. ${ }^{22}$

Como entende McCormick ${ }^{23}$ :

O pensamento progrediu das metas limitadas de proteção da natureza e conservação dos recursos naturais para a visão mais abrangente da má utilização da biosfera por parte dos humanos.

Em segundo lugar, a Conferência permitiu que países subdesenvolvidos fossem ouvidos. Na opinião deles, muitos dos quais estavam iniciando seu desenvolvimento nesta época, a sugestão de crescimento zero para a proteção ambiental era uma medida protecionista, uma artimanha dos países mais desenvolvidos para frear o crescimento dos países emergentes. Na opinião de alguns Estados, com a Índia, o que degradava o meio ambiente era a pobreza, e, para combatê-la, o desenvolvimento era a melhor arma. ${ }^{24}$

A pobreza foi destacada como um dos grandes causadores da poluição. As palavras do chefe da delegação brasileira, José Costa Cavalcanti, resumem bem esta ideia:

A pior poluição é a da pobreza. (...) abrange, nas zonas rurais, a erosão do solo e a deterioraçáo causada por práticas incorretas na agricultura e na exploração florestal. Abrange também condiçóes sanitárias inadequadas e contaminação da água e dos alimentos. Nas zonas urbanas, os problemas são ainda mais complexos, como consequência de densidades urbanas excessivas, com baixos níveis de renda. ${ }^{25}$

Assim, os países menos desenvolvidos conseguiram convencer os países desenvolvidos com relação à algumas questôes, quais sejam: a) as naçôes mais industrializadas eram as que tinham poluído mais até então e, portanto, eram as que deveriam pagar a conta mais alta; b) muitas celeumas ambientais tinham suas raízes na pobreza dos países menos desenvolvidos e, para resolver a pobreza, o crescimento econômico deveria ser a grande

22 McCORMICK, op. cit., p.105.

23 Ibid., p.112.

24 OLIVEIRA, op. cit., p.21-23.

25 José Costa Cavalcanti Apud: ALMEIDA, op. cit., p.18. 
arma; c) o crescimento econômico não era uma ideia oposta ao meio ambiente e sim complementar, pois, somente com ele é que a pobreza seria extirpada e o meio ambiente estaria protegido de suas consequências nefastas; d) o uso dos recursos naturais é uma questão de soberania nacional, cada país deve ter liberdade para decidir como usará seus recursos. ${ }^{26}$

É importante salientar que, o que no início parecia uma vitória dos países menos desenvolvidos, foi posteriormente alvo de muitas críticas. A mídia, cientistas, ecologistas e economistas rotulavam os países em desenvolvimento como inimigos do meio ambiente tendo em vista que sua postura foi a de responsabilizar os países mais desenvolvidos pela degradação ambiental e não se submeterem a nenhum tipo de regra limitadora da utilização dos recursos naturais. ${ }^{27}$

O terceiro resultado da Conferência foi o destaque dado, a partir dela, para as Organizaçôes Não Governamentais - ONG:

As ONGs tiveram pouca influência na conferência em si e nem sempre conseguiram concretizar tanta influência quanto poderiam ter nos fóruns da ONU, mas houve um rápido crescimento do número e da qualidade das ONGs na década pós-Estocolmo. A conferência não somente colocou as ONGs nacionais em contato umas com as outras, mas enfatizou o fato de que enfrentavam problemas comuns que pediam uma resposta combinada. ${ }^{28}$

E, por fim, o quarto resultado da Conferência de Estocolmo foi a instituição do Programa de Meio Ambiente das Naçóes Unidas, um instrumento importante no debate das questóes ambientais internacionais. ${ }^{29}$

Em termos documentais, a reunião produziu a Declaração de Estocolmo, os Princípios e o Plano de Ação, os quais ficariam no papel até que outros ajustes fossem feitos para que eles pudessem serem transformados em políticas e programas efetivamente ativos. No entanto, o alerta já havia sido feito e a humanidade já estava pronta para começar o debate ambiental internacional. As ideias para tal debate já haviam sido lançadas, quais sejam: os recursos naturais são finitos, a humanidade não pode crescer indefinidamente, o crescimento econômico é necessário mas deve ser orientado para a não degradação ambiental. $^{30}$

Então, o final da década de 1960 e início da década de 1970 foi marcado pela tomada de consciência a respeito de problemas ecológicos ligados, principalmente, com

26 ALMEIDA, op. cit., p.19.

27 Ibid., p.19.

28 McCORMICK, op. cit., p.112.

29 Ibid., p.112.

30 Ibid., p.113. 
questôes concretas de poluição industrial, escassez de recursos naturais e crescimento populacional excessivo. ${ }^{31}$

Já em meados da década de 1970 e durante a década de 1980 o grande destaque foi a tomada de consciência a respeito de problemas ambientais globais como: poluiçáo dos oceanos, efeito estufa, escassez de água potável, etc. A partir deste momento, várias discussóes foram travadas no sentido de haver profundas mudanças na forma de compreender o mundo para que se pudesse viver em equilíbrio com o meio ambiente. ${ }^{32}$

Para esta nova compreensão do mundo o homem não poderia mais ter a visão compartimentada, na qual cada assunto está em sua caixinha. A nova visão mundial pedia um olhar amplo, complexo, que pudesse compreender que os assuntos se interrelacionam e que para resolver os problemas devemos compreender estas interrelaçóes, assim como defendia o Clube de Roma, já na década de 1970. E, para a resolução dos problemas ambientais, a postura não poderia ser diferente. Para poder compreender como seria possível harmonizar o desenvolvimento econômico com o meio ambiente também se fez necessário esta visão complexa, esta visão das interrelaçóes entre o desenvolvimento e o meio ambiente. Assim, na década de 1980 vários cientistas, economistas, filósofos, sociólogos, etc... começaram a aprofundar esta visão e publicaram seus estudos. ${ }^{33}$

Em meio a toda esta modificação do pensar, em 1983, onze anos depois da Conferência de Estocolmo, foi criada pela ONU, a Comissão Mundial sobre o Meio Ambiente e Desenvolvimento - CMMAD, sob a presidência de Gro Harlem Brundtland, primeiraministra da Noruega na época. ${ }^{34}$

Os trabalhos da Comissão centravam-se em debater as questóes ambientais globais e propor estratégias de cooperação internacional que pudessem promover as transformaçôes necessárias. ${ }^{35}$

Havia uma frustação internacional no tocante a questão ambiental, muito havia sido feito em teoria: foram criadas várias organizaçôes internacionais, foram assinados muitos documentos, compromissos, etc..., mas, na prática, não havia ocorrido uma mudança de postura, a poluição e a degradação ambiental ainda estavam ocorrendo. Durante os três anos de trabalho em que o Relatório Brundtland foi desenvolvido, muitas catástrofes ambientais ocorreram, como o desastre de Chernobyl, em 1986, o que só reforçou a consciência da comissão de que, muito trabalho ainda deveria ser realizado para que houvesse uma séria modificação no tratamento do meio ambiente pelas nações. ${ }^{36}$

31 BERMEJO, Roberto. La grantransición hacia la sostenibilidad. Madrid: Catarata, 2005. p.23.

32 Ibid., p.23.

33 ALMEIDA, op. cit.. p.24.

34 McCORMICK, op. cit., p.189.

35 Ibid., p.189.

36 COMISSÃO MUNDIAL SOBRE O MEIO AMBIENTE E DESENVOLVIMENTO. Nosso Futuro Comum. 2 ed. Rio de Janeiro: Editora Fundaçăo Getúlio Vargas, 1991.p.XIV. 
Além destas desgraças ecológicas referidas acima, a Comissão realizou vários painéis, ouviu a sociedade civil e constatou que, realmente, nos países menos desenvolvidos, a crise da dívida, a cessação da ajuda internacional, o baixo preço das matérias primas exportadas, a baixa renda individual de sua população levava à pobreza e à degradação ambiental. ${ }^{37}$

Assim, a Comissão chegava ao final dos seus trabalhos com algumas certezas: a) a pobreza é uma das principais causas da degradação ambiental; b) o desenvolvimento é necessário para acabar com a pobreza; c) o desenvolvimento necessário não é só o econômico, é muito mais amplo, é aquele capaz de manter o progresso da humanidade em todos os lugares. ${ }^{38}$

Então, o relatório final desta Comissão, conhecido como Relatório Brundtland, ou Nosso Futuro Comum, foi publicado em 1987 e transformou-se em um marco internacional pois conceituou a expressão desenvolvimento sustentável e a cunhou no cenário internacional, sendo aceito por mais de 100 países. ${ }^{39}$

A conclusóes do relatório indicavam que meio ambiente e desenvolvimento estavam intimamente conectados e que as respostas políticas dadas até então não eram suficientes pois tratavam destes assuntos de forma separada. E ainda, as soluçóes políticas tratavam de criar mais empregos, produzir mais alimentos, mais energia, mais bens, e não tratavam de poupar os recursos ambientais que sustentavam tudo isso. Aliado a isso, neste momento, havia a consciência de que, qualquer decisão interna sobre o meio ambiente poderia ter efeito além fronteiras (por exemplo, a poluição ácida de algumas fábricas transpunha a fronteira dos países que permitiam a liberação de gases tóxicos na atmosfera). ${ }^{40}$

A comissão em seu relatório advertiu que a questão ambiental ainda era relegada a um plano de menor importância e isso não poderia mais ocorrer, era necessário que ela fosse colocada de lado a lado das questóes econômicas e sociais quando da tomada de decisóes políticas. ${ }^{41}$

Assim, o Relatório Nosso Futuro Comum definiu o que seria desenvolvimento sustentável como aquele que permite: "o atendimento das necessidades do presente sem comprometer a possibilidade de as geraçóes futuras atenderem as suas próprias necessidades." 42

37 COMISSÃO MUNDIAL SOBRE O MEIO AMBIENTE E DESENVOLVIMENTO. Nosso Futuro Comum. p.XIV.

38 COMISSÃO MUNDIAL SOBRE O MEIO AMBIENTE E DESENVOLVIMENTO. Nosso Futuro Comum.p.4.

39 BERMEJO, Roberto. op. cit., p.23.

40 McCORMICK, op. cit. p.189.

41 Ibid., p.190.

42 COMISSÃO MUNDIAL SOBRE O MEIO AMBIENTE E DESENVOLVIMENTO. Nosso Futuro Comum, p.46. 
O próprio Relatório explica que há dois componentes do conceito de desenvolvimento sustentável. O primeiro componente do conceito é que, o desenvolvimento sustentável deve ser pautado no atendimento das necessidades essenciais das pessoas, e, satisfeitas estas necessidades, devem ser dadas oportunidades para que as pessoas concretizem o seu desejo de uma vida melhor. O segundo componente é que o desenvolvimento sustentável está limitado, em virtude do estado atual da tecnologia e da organização social, pelo meio ambiente, ou seja, as atividades humanas não podem ignorar as limitações dos recursos naturais. ${ }^{43}$

Da leitura destes dois componentes pode-se inferir uma dimensão social, que aparece quando o conceito se preocupa com a satisfação das necessidades básicas das pessoas; uma dimensão ambiental, quando o conceito exprime a preocupaçáo com a limitação dos recursos naturais e uma dimensão econômica, quando o conceito menciona a palavra desenvolvimento.

Ao que tudo indica, segundo o Relatório Nosso Futuro Comum, tal satisfação de necessidades básicas só ocorre com o crescimento, o qual deve respeitar as limitaçôes ambientais. ${ }^{44}$ Este crescimento deve ir além da questão econômica e envolver a questão social, deve ser capaz de manter o progresso da humanidade em todos os cantos do planeta. ${ }^{45}$

Percebe-se que tal conceito é bastante genérico, ele determina o que tem que ser feito, mas não determina como. E ainda, ao mencionar o atendimento das necessidades básicas o relatório não as delimita o que é um problema pois, a sua conceituação varia dependendo do tipo de sociedade e do seu estado de evolução. O que é necessidade básica na Índia pode não ser necessidade básica nos EUA. Talvez por isso esta conceituação de desenvolvimento sustentável tenha conseguido a aprovação de tantos países, pois, sua generalidade permite várias interpretaçôes dependendo da visão, da ideologia, dos valores e dos interesses que são levados em consideração. ${ }^{46}$

Esta conceituação recebeu, e ainda recebe, muitas críticas. Primeiro porque, entendem alguns, que ela exprime uma ideia comum, a de que as atuais geraçóes devem se preocupar com as geraçôes futuras. E isto já foi realizado por tantas outras civilizaçôes antes da nossa. Em segundo lugar, há quem entenda que desenvolvimento e a sustentabilidade são ideias contraditórias e assim, não há como compatibilizar o desenvolvimento econômico, que não tem limites, com a proteção dos recursos naturais, os quais são limitados. E em terceiro lugar, há quem diga que o conceito proposto pelo Relatório Brundtland é

43 COMISSÃO MUNDIAL SOBRE O MEIO AMBIENTE E DESENVOLVIMENTO. Nosso Futuro Comum. p.46.

44 BERMEJO, op. cit., p.25.

45 COMISSÃO MUNDIAL SOBRE O MEIO AMBIENTE E DESENVOLVIMENTO. Nosso Futuro Comum. p.4.

46 BERMEJO, op. cit., p.24. 
bastante economicista pois preocupa-se em gerir os recursos para as geraçóes futuras, mas não há preocupação quanto a gestão dos recursos para as atuais geraçôes, o que se mostra imprescindível se há a intenção de programar o futuro. ${ }^{47}$

Após a publicação do Relatório Nosso Futuro Comum muitos outros eventos internacionais foram realizados e tais eventos, em alguns momentos, geraram mais confusão sobre esta conceituação e, em outros momentos, promoveram uma outra direção, a direção da sustentabilidade, a qual será abordada mais adiante.

No cenário internacional, muitas vezes a expressão desenvolvimento sustentável vem carregada de sentido econômico, querendo expressar mais uma desculpa para incentivar o desenvolvimento do que realmente uma preocupação com o futuro da humanidade. No entanto, ela continua sendo utilizada nos debates nacionais e internacionais e aparece em vários relatórios importantes.

O fato é que o Relatório Nosso Futuro Comum deu visibilidade internacional aos assuntos: proteção ambiental e desenvolvimento. A grande conquista deste documento foi inserir o debate interligado destes temas nas discussóes entre países desenvolvidos e subdesenvolvidos e em suas políticas internas.

A seguir serão abordados outros eventos e documentos internacionais que levaram a humanidade a pensar além do desenvolvimento sustentável, a pensar a sustentabilidade.

\section{Novos Eventos Internacionais e o Caminho para o Conceito de Sustentabi- lidade}

O início da década de 1990 foi marcado pela divulgação, pela ONU, do Relatório de Desenvolvimento Humano - RDH. Referido relatório foi divulgado pela primeira vez em 1990 tendo sido idealizado por Mahbub ul Haq, economista paquistanês, e por Amartya Sen, economista indiano. ${ }^{48}$

A ONU, premida pelas últimas discussóes internacionais sobre qual o tipo de desenvolvimento a ser adotado para a perpetuação da espécie humana na terra, publicou este relatório baseado no Índice de Desenvolvimento Humano - IDH. Tratava-se de uma nova medida geral do desenvolvimento humano que se contrapunha ao Produto Interno Bruto - PIB per capita, índice que considerava, e ainda considera, apenas a dimensão econômica do desenvolvimento. ${ }^{49}$

47 VILCHES, Amparo; MACÍAS, Óscar; PÉREZ, Daniel Gil. La transición a la sostenibilidad: un desafio urgente para la ciência, la educación y la acción ciudadana. Andalucia: Iberciencia. 2014. p.9-11

48 PROGRAMA DAS NAÇÕES UNIDAS PARA O DESENVOLVIMENTO - PNUD. Disponível em: http://www.pnud.org.br/IDH/IDH.aspx?indiceAccordion=0\&li=li_IDH. Acesso em 13.10.2014.

49 PROGRAMA DAS NAÇÓES UNIDAS PARA O DESENVOLVIMENTO - PNUD. Disponível em: http://www.pnud.org.br/IDH/IDH.aspx?indiceAccordion=0\&li=li_IDH. Acesso em 13.10.2014. 
O IDH ampliava a perspectiva sobre o desenvolvimento humano ao levar em consideração indicadores sobre saúde, educação e renda. ${ }^{50} \mathrm{~A}$ divulgação do $\mathrm{RDH}$ mostrou, por meio de análises matemáticas, que o crescimento econômico era apenas um dos ingredientes de um processo muito mais amplo que levaria ao desenvolvimento humano. ${ }^{51}$

Este documento produzido pela ONU influenciou outras discussóes internacionais pois possibilitou uma análise multifacetada do desenvolvimento humano e náo somente econômica (como a realizada através do PIB per capita), em que pese a própria Organização reconhecer que ele náo engloba todos os aspectos do desenvolvimento, tais como: democracia, equidade e sustentabilidade. ${ }^{52}$

Em 1992 ocorreu a Conferência da ONU sobre Meio Ambiente e Desenvolvimento - CNUMAD, também conhecida como Rio-92, Eco-92 ou ainda Cúpula da Terra, que tinha como lema "De uma Terra... a um Mundo". Tal lema foi estabelecido justamente para mostrar que o pensamento ambiental havia avançado aumentando-se o âmbito das preocupaçôes: de local para global, principalmente depois da divulgação do $\mathrm{RDH}$, citada acima. ${ }^{53}$

A Eco-92 adotou cinco documentos de grande importância: a Agenda 21, a Declaração do Rio sobre Meio Ambiente e Desenvolvimento, a Convenção sobre Florestas, a Convenção Sobre Mudanças Climáticas, e a Convenção sobre Diversidade Biológica. ${ }^{54}$

No entanto, a Agenda 21 e a Declaração do Rio sobre Meio Ambiente e Desenvolvimento foram os documentos mais marcantes.

A Agenda 21 fazia um diagnóstico dos problemas que precisavam de solução urgente e a identificação de quais os recursos e quais os meios necessários para resolvê-los, além de fixar metas para os próximos anos. ${ }^{55}$

Tratava-se de um acordo internacional com quarenta capítulos divididos em quatro secçóes. A primeira abordava as dimensóes sociais e econômicas e apresentava os problemas que deveriam ser resolvidos: a pobreza, saúde, crescimento da população, assentamentos humanos, dívidas públicas, comércio, entre outros. A segunda secção tratava da conservação e gestão de recursos para o desenvolvimento, a terceira tratava do

50 PROGRAMA DAS NAÇÓES UNIDAS PARA O DESENVOLVIMENTO - PNUD. Disponível em: http://www.pnud.org.br/IDH/IDH.aspx?indiceAccordion=0\&li=li_IDH. Acesso em 13.10.2014.

51 VEIGA, José Eli da. Desenvolvimento sustentável-O desafio do Sec. XXI. 1ª. ed. Rio de Janeiro: Garamond, 2005. v. 1. p.31.

52 PROGRAMA DAS NAÇÓES UNIDAS PARA O DESENVOLVIMENTO - PNUD. Disponível em: http://www.pnud.org.br/IDH/IDH.aspx?indiceAccordion=0\&li=li_IDH. Acesso em 13.10.2014.

53 Rafael Hurtado Rodero in ROBLEDO, Irene Saavedra (coord.). Introducción a la sostenibilidad y la RSC. p.11.

54 Rafael Hurtado Rodero in ROBLEDO, op. cit., p.11.

55 CONSEJO DE LA TIERRA E INSTITUTO INTERAMERICANO DE COOPERACCIÓN PARA LA AGRICULTURA. La cumbre de la tierra ECO 92: visiones diferentes. São José, CR: IICA, 1993. p.12. 
fortalecimento do papel dos grupos sociais e a quarta dos meios de instrumentação, ou seja, abordava os recursos e instrumentos necessários para por em prática as políticas de desenvolvimento sustentável. ${ }^{56}$

Já a Declaração do Rio sobre Meio Ambiente e Desenvolvimento, tinha vinte e sete princípios. Todos foram estabelecidos com o objetivo de promover uma aliança global justa e igualitária, com base na cooperação internacional entre os Estados, os setores-chave da sociedade e as pessoas. Diante disso, esta declaraçáo buscou promover a realizaçáo de acordos internacionais para a proteção do meio ambiente frente ao desenvolvimento mundial. ${ }^{57}$

Ao abordar as questóes sobre pobreza, saúde, assentamentos humanos, entre outros, e, em meio às discussóes resultantes da divulgação do IDH, a Eco-92 promove a evolução dos debates. Mostra ao mundo que o desenvolvimento sustentável não se faz apenas com prosperidade econômica e qualidade ambiental, mas também com justiça social, com preocupaçáo com os seres humanos e sua dignidade, elementos que até agora eram desprezados. ${ }^{58}$

Finalizada a Eco-92, a ONU criou um novo mecanismo institucional, a Comissão de Desenvolvimento Sustentável - CDS, cuja função era dar encaminhamento a todos os assuntos lá debatidos. Em 1997 a CDS reuniu-se em Nova Iorque, reunião que ficou conhecida como Rio+5, com o intuito de revisar o grau de cumprimento das propostas da Eco-92 e impulsionar o desenvolvimento sustentável. Nesta reunião foi aprovada a ideia da realização de uma Conferência Mundial sobre Desenvolvimento Sustentável. ${ }^{59}$

Enquanto a referida conferência era preparada, a ONU resolveu realizar uma nova reunião entre todos os seus membros. Em virtude da chegada do novo milênio, a Organização viu a oportunidade de estimular seus membros a discutir o papel que a mesma desempenharia no século XXI. Muitos avanços haviam ocorrido no século anterior: a expectativa de vida havia aumentado, as pessoas gozavam de mais saúde, alimentavam-se melhor, etc... No entanto, havia também muitas coisas a serem corrigidas ou extintas, como: a pobreza, as epidemias, a depredação ambiental, as guerras, enfim, havia bastante assunto a ser debatido nesta reuniáo que ficou conhecida como "Cúpula do Milênio". ${ }^{60}$

56 CONSEJO DE LA TIERRA E INSTITUTO INTERAMERICANO DE COOPERACCIÓN PARA LA AGRICULTURA. La cumbre de la tierra ECO 92: visiones diferentes. São José, CR: IICA, 1993. p.12.

57 CONSEJO DE LA TIERRA E INSTITUTO INTERAMERICANO DE COOPERACCIÓN PARA LA AGRICULTURA. La cumbre de la tierra ECO 92: visiones diferentes. São José, CR: IICA, 1993. p.15.

58 ELKINGTON, John. Canibais com garfo e faca. São Paulo: Makron Books, 2000. p.74-75.

59 Rafael Hurtado Rodero in ROBLEDO, op. cit., p.11-12.

60 ANNAN, Kofi A. "Nós os Povos": O papel das Naçōes Unidas no século XXI. Genebra: Organização das Naçôes Unidas, 2000. p. 5. 
Assim, em setembro de 2000, 189 países reunidos na sede da ONU em Nova Iorque aprovaram a Declaração do Milênio, tratava-se de uma lista de objetivos de desenvolvimento econômico, social e ambiental bastante ambiciosa. A partir dela foram traçados os Objetivos de Desenvolvimento do Milênio - ODM, uma lista de oito objetivos básicos, os quais foram divididos em 18 metas com 48 indicadores. A ideia é que tais objetivos fossem alcançados até $2015 .{ }^{61}$ Restou claro com esta declaração que os membros da ONU estavam agora comprometidos em empreender uma tarefa hercúlea: a de adotar objetivos e metas comuns capazes de construir uma sociedade livre, igualitária, solidária, tolerante, com respeito à natureza e com responsabilidade comum. Esta declaração foi ratificada pela Conferência de Joanesburgo, também chamada de Conferência Mundial sobre Desenvolvimento Sustentável, ocorrida em 2002 e inspirou os debates lá travados. ${ }^{62}$

A supracitada Conferência Mundial tinha o objetivo de construir um modelo de desenvolvimento sustentável, a ser aplicado globalmente, e que levasse em consideração o desenvolvimento econômico e social e a proteção ambiental. ${ }^{63}$

A reunião de Joanesburgo tentou implementar medidas práticas e efetivas pois, mesmo tendo ocorrido alguns avanços na área da sustentabilidade desde 92 , eles não foram suficientes para modificar algumas práticas insustentáveis e que estavam agravando determinadas situaçóes no planeta. Foram firmados acordos, compromissos e planos de atuação no tocante a escassez da água potável, à energia, gestão de recursos naturais, saneamento básico, biodiversidade, entre outras matérias. Inclusive foi apoiada a criação de um fundo internacional para erradicação da pobreza. ${ }^{64}$

Para Gabriel Real Ferrer, foi a partir do estabelecimento dos ODM e da Conferência de Johanesburgo que passou-se a utilizar o conceito de sustentabilidade como algo diferente de desenvolvimento sustentável. A sustentabilidade passa a ser a meta de uma aliança global para encarar os principais desafios da humanidade ${ }^{65}$.

\section{Diferenças entre os Conceitos de Desenvolvimento Sustentável e Susten- tabilidade}

Cabe destacar que há muita confusão acerca da utilização dos termos desenvolvimento sustentável e sustentabilidade. Confusão esta que pode ser perigosa e acabar

61 ALMEIDA, Fernando. Os desafios da sustentabilidade. Rio de Janeiro: Elsevier. 2007. p.77.

62 ORGANIZAÇÃO DAS NAÇŌES UNIDAS. Declaração do Milênio. Cimeira do Milênio. Nova Iorque, 6-8 de setembro de 2000. Lisboa: Centro de Informaçōes das Naçōes Unidas, 2001. p.3-4.

63 Rafael Hurtado Rodero in ROBLEDO, op. cit., p.12.

64 Rafael Hurtado Rodero in ROBLEDO, op. cit., p.12.

65 REAL FERRER, Gabriel. El Principio de no regresión ambiental a la luz delparadigma de la Sostenibilidad. Material disponível para os alunos do Curso de Doutorado em Ciências Jurídicas da Universidade do Vale do Itajaí em convênio de dupla Titulação com a Universidade de Alicante na Espanha. p. 2. 
banalizando um assunto tão importante. Por isso, é de suma importância que sejam discutidos os exatos limites de ambos os termos para que as palavras não os levem ao esquecimento, banalização ou modismo. ${ }^{66}$

Parte desta confusão ocorre em virtude do que se entende por desenvolvimento. No dicionário desenvolvimento significa o ato ou efeito de desenvolver ${ }^{67}$, ou seja, de crescer, progredir, aumentar. ${ }^{68}$

Assim, na maioria das vezes, a palavra desenvolvimento é usada para designar algo que irá aumentar, e, para que o aumento ocorra é necessário que recursos sejam consumidos.

Para alguns doutrinadores, como Daly ${ }^{69}$, crescimento e desenvolvimento possuem diferenças. Crescimento significa aumento de tamanho pela adição de materiais; enquanto o desenvolvimento significa expandir, trazendo gradualmente para um melhor estado. Assim, para o autor, o crescimento é quantitativo e desenvolvimento é qualitativo.

Portanto o crescimento seria algo insustentável afinal, tendo como base o consumo dos recursos naturais, não poderia perdurar por muito tempo devido a limitação dos mesmos. Já o desenvolvimento poderia ser sustentável tendo em vista que seu objetivo seria a evolução o progresso para uma melhor condição. ${ }^{70}$

O Relatório de Desenvolvimento Humano - RDH de 1990, citado no tópico anterior, já usava a palavra desenvolvimento como um processo de alargamento das escolhas das pessoas, teoria que, posteriormente foi publicada por Amartya Sen ${ }^{71}$ em 1999 em sua obra Desenvolvimento como Liberdade.

Para $\operatorname{Sen}^{72}$, o desenvolvimento está intimamente ligado a expansão da garantia das liberdades individuais. Ele não pode ser medido apenas por índices econômicos como o PIB (produto interno bruto), mas deve ser medido pela possibilidade que um Estado tem de expandir as liberdades individuais do seu povo.

66 REAL FERRER, Gabriel. Sostenibilidad, transnacionalidad y trasformaciones del derecho. Material disponível para os alunos do Curso de Doutorado em Ciências Jurídicas da Universidade do Vale do Itajaí em convênio de dupla Titulação com a Universidade de Alicante na Espanha. p.4.

67 FERREIRA, Aurélio Buarque de Holanda. Dicionário Aurélio básico da lingua portuguesa. Disponível em http://www.dicionariodoaurelio.com/desenvolvimento. Acesso em 17/03/2015.

68 FERREIRA, Aurélio Buarque de Holanda. Dicionário Aurélio básico da língua portuguesa. Disponível em http://www.dicionariodoaurelio.com/desenvolver. Acesso em 17/03/2015.

69 DALY, Herman E. Toward some operational principles of sustainable development. Ecological Economics, v.2, p.1-6, 1990.

70 DALY, Herman E. Toward some operational principles of sustainable development. Ecological Economics, v.2, p.1-6, 1990.

71 SEN, Amartya. Desenvolvimento como liberdade. 1. ed. São Paulo: Companhia de Bolso, 2010.

72 Ibid. p.16-26. 
Problemas como a pobreza, a tirania, a carência de oportunidades econômicas, a exclusão social, os serviços públicos inexistentes ou deficitários, a interferência excessiva dos Estados, acontecem em várias nações, sejam elas ricas ou pobres e, para o autor, não há dúvida que o seu combate passa pela garantia da liberdade individual. A expansão desta liberdade é vista por Sen como o fim e o principal meio do desenvolvimento. Desenvolvimento significa extirpar tudo o que limite a liberdade individual, tudo o que imponha limite às escolhas das pessoas. ${ }^{73}$

Assim, o crescimento econômico e o desenvolvimento podem ser formas de expandir as liberdades individuais, mas não as únicas, há outros caminhos que devem ser utilizados pois os problemas são de várias ordens: econômica, social e ambiental.

Um cidadão livre é aquele que pode escolher se quer ou não trabalhar, para quem quer trabalhar, bem como quando quer trabalhar. A impossibilidade de fazer estas escolhas prejudica o desenvolvimento. ${ }^{74}$

A partir da leitura da obra de $\operatorname{Sen}^{75}$ compreende-se que o desenvolvimento ocorre quando o povo tem a liberdade de escolha do seu destino e para que ela possa ser adquirida é necessário que o povo tenha acesso às suas necessidades básicas. E, este acesso às necessidades básicas se consegue quando são promovidas as condiçóes dignas para que o povo trabalhe, obtenha recursos, e faça sozinho a gestáo de sua vida, o que pode ser consequência do crescimento econômico, do desenvolvimento, mas também, e na maioria das vezes, de uma série de políticas públicas e/ou privadas.

No entanto, mesmo depois de toda esta explicação acerca do significado de crescimento e de desenvolvimento o que se percebe é que, a palavra desenvolvimento ainda é dotada de forte conotação econômica, é muito mais comum ligar desenvolvimento com expansão quantitativa do que com expansão qualitativa, como querem Daly e Sen.

Para este artigo o desenvolvimento será compreendido nas óticas de Daly e Sen, ou seja, como uma expansão qualitativa, como um processo que visa levar à melhor condição.

Neste sentido, a expressão desenvolvimento sustentável nada mais é do que uma forma de dar ao desenvolvimento a qualidade de sustentável. Trata-se do desenvolvimento que, por meio da expansão qualitativa e, na busca pela melhoria da condição atual, é compatível com a manutenção da capacidade dos sistemas naturais de suportarem a existência humana. ${ }^{76}$

Assim, se na expressão desenvolvimento sustentável o que qualifica o desenvolvimento como algo diferente, especial, capaz de trazer soluçóes é a palavra sustentabilidade, é o seu conceito que temos que buscar.

73 Ibid. p. 16-77.

74 Ibid. p. 16-26.

75 Ibid. p. 16-26.

76 REAL FERRER, Gabriel. Sostenibilidad, transnacionalidad y trasformaciones del derecho. p. 3. 
Após o estabelecimento dos Objetivos do Desenvolvimento do Milênio e da Conferência de Johanesburgo, a comunidade internacional compreendeu que, a sustentabilidade é metal global, é o objetivo que os países membros da ONU querem alcançar. E, assim sendo, o desenvolvimento se mostra como um dos caminhos para o alcance deste objetivo. Deve ficar claro que, nem sempre o caminho para a sustentabilidade será o do desenvolvimento, é necessário ser flexível neste sentido, sob pena de não se alcançar o objetivo. ${ }^{77}$

Como entende Edgar Morin: "É preciso simultaneamente mundializar e desmundializar, crescer e decrescer, desenvolver e reduzir, conservar e transformar." É esta multiplicidade de caminhos que, em conjunto, podem criar um novo caminho, uma nova via como ele chama. ${ }^{78}$

A Rio + 20 contribuiu para a dissociação de desenvolvimento sustentável e sustentabilidade, quando em seu primeiro ponto indicou que os Chefes de Estado e de Governo lá reunidos renovavam seu compromisso com o desenvolvimento sustentável e com a promoção de um futuro econômico, social e ambientalmente sustentável (que nada mais é do que a sustentabilidade). Assim, na declaração da Rio + 20 houve o compromisso com as duas noçôes, a de Desenvolvimento Sustentável e a de Sustentabilidade. ${ }^{79}$

Desta forma, para este trabalho de pesquisa, resta claro que as duas expressóes possuem conotaçôes diferentes e que a expressão Desenvolvimento Sustentável é mais restrita por dizer respeito a apenas um dos caminhos possíveis para a sustentabilidade.

Resta agora aprofundar o conceito de sustentabilidade para melhor compreensão de todo o aqui exposto.

\section{0 Conceito de Sustentabilidade}

Inicialmente destaca-se que, muito se tem publicado sobre o conceito de sustentabilidade. Desde a divulgação do Relatório Nosso Futuro Comum várias obras surgiram tentando explicar o que seria este adjetivo, esta palavra que é capaz de caracterizar um substantivo como o desenvolvimento, como a administração de uma empresa, como a política de um governo, etc...

Conforme explica Klaus Bosselmann ${ }^{80}$, a ideia de sustentabilidade é semelhante a ideia de justiça. A maioria das pessoas sabe o que é por intuição e, por este ângulo, o conceito

77 REAL FERRER, Gabriel. Sostenibilidad, transnacionalidad y trasformaciones del derecho. p. 4.

78 MORIN, Edgar. A Via: para o futuro da humanidade. Tradução de Edgard de Assis Carvalho e Mara Perassi Bosco. Rio de Janeiro: Bertrand Brasil, 2013. p. 41.

79 REAL FERRER, Gabriel. Sostenibilidad, transnacionalidad y trasformaciones del derecho. p. 8.

80 BOSSELMANN, Klaus. The principle os sustentability: transforming law and governance. Hampshire: Ashgate, 2008. p.9. 
parece simples. É possível que muitas pessoas consigam imaginar como seria uma sociedade sustentável, no entanto, não se sabe como chegar até ela pois, na verdade, não há um conceito uniforme sobre o que seria uma sociedade sustentável, e o debate sobre ele exige reflexão sobre os valores e princípios que embasarão o futuro da humanidade.

Atualmente, todos querem um mundo sustentável, não há uma pessoa que se atreva a dizer que não deseja a sustentabilidade. No entanto, ela parece mais difícil de alcançar do que a justiça, e há várias razóes para isso, tais como: a) o fato de que muitas sociedades são descritas como justas, pelo menos do ponto de vista de conseguirem solucionar pacificamente seus conflitos, no entanto, nenhuma sociedade atualmente é descrita como sustentável; b) a injustiça é muito menos tolerada do que a insustentabilidade. Nos dias de hoje, regimes políticos que geram injustiças não duram muito tempo pois o povo se revolta contra eles, no entanto, sociedades insustentáveis vão sobrevivendo pois os efeitos não são imediatamente sentidos, eles chegam aos poucos e certamente serão agravados nas futuras geraçóes. ${ }^{81}$

Assim, a emergência para a sustentabilidade parece ter ganhado força apenas após a ocorrência de desgraças ambientais, conforme foi amplamente exposto nos subitens acima. A cada desgraça ambiental uma nova onda de discussóes sobre a relação entre o homem e a natureza tinha início.

O fato é que a palavra sustentabilidade existe há muito tempo, muito antes da ONU buscar a definição de desenvolvimento sustentável. A primeira vez que ela foi usada foi em uma obra de Hans Carl von Carlowitz, que publicou em 1713 um tratado intitulado Sylvicultura Oeconomica, onde usou a palavra pela primeira vez. ${ }^{82}$

O livro foi escrito em uma época de crise europeia devido a escassez de recursos florestais. As florestas haviam sido devastadas para a utilização da lenha como combustível e como matéria prima da construção civil. Carlowitz defendia que a integridade ecológica deveria ser respeitada e não poderia ser comprometida. Para o autor a sustentabilidade, a longo prazo, do que ele chamava de "esfera comum", era preservar os estoques de recursos naturais, os quais deveriam determinar o que os humanos poderiam ou não usar, naquele momento e no futuro. ${ }^{83}$

Ainda, para o autor, as questóes econômicas e sociais deveriam ser mensuradas com respeito aos estoques de recursos naturais disponíveis. Assim, o centro do conceito de sustentabilidade para Carlowitz era a natureza. ${ }^{84}$

81 BOSSELMANN, Klaus. The principle os sustentability: transforming law and governance. p.9-10.

82 CARLOWITZ, H. C. von. Sylvicultura oecoomica. 1713. Apud BOSSELMANN, Klaus. The principle os sustentability: transforming law and governance. p.18-19.

83 Ibid. p.18-19.

84 Ibid. p.18-19. 
A teoria de Carlowitz tem grande importância na atualidade tendo em vista que influenciou a construção de uma série de modelos que propóe a natureza como o principal valor da sustentabilidade.

Após este breve relato histórico sobre a primeira aparição da palavra sustentabilidade, entende-se importante verificar o significado que apresenta o dicionário. No Dicionário Aurélio a sustentabilidade aparece como um adjetivo, como uma "qualidade ou condição do que é sustentável." ${ }^{85}$ E sustentável é aquilo "que se pode sustentar, ou que tem condiçôes para se manter ou conservar" ${ }^{86}$

Assim sendo, verificam-se duas conotações: uma passiva, na qual sustentável é algo que se pode segurar ou impedir que caia, e ainda uma conotação ativa, na qual sustentável é algo que tem condiçốes de se manter, de se conservar, de se perpetuar. ${ }^{87}$

Como se está tratando de uma palavra que teve origem na área da ecologia é importante que se ressalte que a palavra sustentabilidade surgiu para definir o conjunto de procedimentos capazes de manter um sistema "vivo, protegido, alimentado de nutrientes, ao ponto que sempre esteja se conservando." 88

Portanto, em ecologia, a palavra sustentabilidade tem a conotação ativa acima exposta, pois, sustentável é aquele sistema que tem condiçóes de se manter, de se preservar.

Desta forma, pode-se compreender que, na visão ecológica (a qual deu origem a palavra), se o objetivo é construir um mundo sustentável, o trabalho deve ser empreendido no sentido de criar um conjunto de procedimentos que seja capaz de manter este mundo vivo, alimentando-o e cuidando-o para que os recursos para esta manutenção não acabem. E, é claro, que não se pode pensar apenas em recursos naturais, o mundo sustentável que se almeja deve ter todas as formas de vida para que se perpetue em equilíbrio.

Compreendendo estas ideias preliminares é possível entender os mais variados conceitos de sustentabilidade que os cientistas dos dias de hoje apresentam. $\mathrm{Na}$ verdade, todos estes conceitos são permeados pelas ideias acima expostas.

Leonardo Boff ${ }^{89}$ expõe sua visão holística de sustentabilidade. Para ele, a chave está em compreender que, como centro do conceito de sustentabilidade não deve estar o homem, mas sim a vida. O trabalho a ser empreendido deve ser pautado em criar os

85 FERREIRA, Aurélio Buarque de Holanda. Dicionário Aurélio básico da língua portuguesa. Disponível em http://www.dicionariodoaurelio.com/sustentabilidade. Acesso em: 17.03.2015.

86 FERREIRA, Aurélio Buarque de Holanda. Dicionário Aurélio básico da lingua portuguesa. Disponível em http://www.dicionariodoaurelio.com/sustentavel. Acesso em: 17.03.2015.

87 BOFF, Leonardo. La sostenibilidad: Que es y qué no es. Trad. Jesús García-Abril. Maliaño: Editorial Sal Terrae. 2013. p.22.

88 Ibid., p.22.

89 Ibid., p.21-44. 
mecanismos para que todo o tipo de vida se sustente. $O$ homem é apenas parte da vida que existe sobre a terra, há ainda os animais, as plantas, etc... e todas estas formas de vida devem ser respeitas e cuidadas.

Já para Real Ferrer ${ }^{90}$ a sustentabilidade é:

(...) a capacidade de permanecer indefinidamente no tempo, o que, aplicado a uma sociedade que obedeça a nossos padrôes culturais e civilizatórios supóe que, ademais de adaptar-se a capacidade do entorno natural em que se desenvolve, alcance os níveis de justiça social e econômica que a dignidade humana exige.

Para o autor acima citado, a construção de um mundo sustentável exige uma série de compromissos e açóes. Primeiro deve-se considerar que a sociedade é planetária. Dividimos o mesmo planeta e assim somos todos responsáveis por ele na mesma medida, portanto, nossas açóes sempre devem levar em consideração que vivemos na mesma comunidade global. ${ }^{91}$

Em segundo lugar deve-se ter um compromisso com a terra. Não se pode continuar pressionando o capital natural, é necessário reduzir a demanda sobre ele até que alcance um patamar razoável o qual permita a utilização e reposição dos recursos de forma equilibrada. ${ }^{92}$

Deve-se ainda ser capaz de promover a dignidade humana, não de apenas um grupo de pessoas mas de toda a comunidade global. São seres humanos, são nossos semelhantes, e merecem ter uma vida adequada sem miséria, sem fome e sem desigualdade social. A condição humana degradante, a qual é vista em várias parte do globo terrestre, é insustentável. ${ }^{93}$

Em quarto lugar, deve-se recompor o que o autor chama de arquitetura social. O conforto e o bem estar de uma camada social não deve ser construído em cima da desgraça de outras camadas da sociedade, deve-se lutar pela justiça social.

É necessário, em quinto lugar, criar novas formas de governança mundial que coloquem o interesse geral frente aos interesses individuais. A globalização deve ser colocada a serviço das pessoas e não o contrário. Há que ser incrementada e incentivada a participação política do povo, com base na democracia participativa. ${ }^{94}$

Por fim, é indispensável, colocar a ciência e a técnica a serviço do bem comum. O progresso tecnológico é uma faca de dois gumes. Tem importância destacada, no entanto,

90 REAL FERRER, Gabriel. Sostenibilidad, transnacionalidad y trasformaciones del derecho. p.4.

91 REAL FERRER, Gabriel. Sostenibilidad, transnacionalidad y trasformaciones del derecho.p.7-8.

92 REAL FERRER, Gabriel. Sostenibilidad, transnacionalidad y trasformaciones del derecho.p.7-8.

93 REAL FERRER, Gabriel. Sostenibilidad, transnacionalidad y trasformaciones del derecho.p.7-8.

94 REAL FERRER, Gabriel. Sostenibilidad, transnacionalidad y trasformaciones del derecho.p.7-8. 
inspira cuidados, pois deve ser feito de forma orientada, só tendo sentido se for direcionado ao bem comum e não a geração de tecnologias perigosas que podem gerar conflitos, novas bactérias, ou ainda mais resíduos ambientais irrecuperáveis. ${ }^{95}$

As visóes acima apontadas possuem uma diferença bem clara, Real Ferrer centra o conceito de sustentabilidade na perpetuação da espécie humana e Leonardo Boff tem a sua visão holística concentrando o conceito de sustentabilidade na perpetuação de todas as formas de vida, ou seja, coloca a natureza como valor principal da sustentabilidade, como fazia Carlowitz.

Desta forma, percebe-se que o conceito de sustentabilidade não é único e nem estático, ele está em construção, sendo constantemente alterado, acrescido, incrementado.

\section{Conclusões}

Este artigo iniciou tratando de um breve relato histórico sobre o surgimento da expressáo desenvolvimento sustentável, para, posteriormente, apresentar o seu conceito. Em seguida foram apontados alguns eventos internacionais que contribuíram para a construção do conceito de sustentabilidade e, por fim, abordou-se o seu conceito, o qual é de vital importância para a sobrevivência da espécie humana.

Diante do que foi exposto, percebe-se que as expressóes desenvolvimento sustentável e sustentabilidade são diferentes. $\mathrm{O}$ crescimento econômico e o desenvolvimento sustentável podem ser diferentes vias para o alcance da sustentabilidade, mas não as únicas. $\mathrm{O}$ alcance da sustentabilidade necessita de estratégias nas áreas social, ambiental, econômica e tecnológica.

Já quanto ao conceito de sustentabilidade, tão necessário nos dias de hoje, é importante destacar que, independente do centro da teoria utilizada (se a espécie humana ou a vida), os autores citados acima, concordam náo ser possível seguir no caminho atual e que há a necessidade urgente de uma mudança de padrão para alcançarmos a sociedade do futuro: justa, igualitária e respeitosa da natureza.

Para Real Ferrer, devemos almejar:

(...) Uma sociedade que não colapse os sistemas naturais que, ademais, nos permita viver em paz com nós mesmos, mais justa, mais digna, mais humana. Uma sociedade que dê um salto significativo no progresso civilizatório, que deixe para trás ou ao menos amenize os grandes males da Humanidade que a todos deve avergonhar, como a fome, a miséria, a ignorância e a injustiça. $\mathrm{O}$ paradigma atual da Humanidade

95 REAL FERRER, Gabriel. Sostenibilidad, transnacionalidad y trasformaciones del derecho.p.7-8. 
é a sustentabilidade. A vontade de articular uma nova sociedade capaz de perpetuar-se no tempo em condiçôes dignas. A deterioração material do planeta é insustentável, mas também é insustentável a miséria, a exclusão social, a injustiça, a opressão, a escravidão e a dominação cultural e econômica.

Já Boff ${ }^{96}$ indica o que não se deve fazer na busca por esta sociedade:

“(...) pouco importa a concepção que tenhamos da sustentabilidade, sua ideia matriz é esta: não é correto, nem justo, nem ético que, ao buscar os meios para nossa subsistência, dilapidemos a natureza, destruamos os biomas, envenenemos os solos, contaminemos as águas, o ar e destruamos o sutil equilíbrio do sistema - Terra e do sistema-vida. Não é eticamente tolerável que determinadas sociedades vivam a custa de outras sociedades ou de outras religióes, nem que a sociedade humana atual viva subtraindo as geraçóes futuras dos meios necessários para que possam viver decentemente.”

Todas as posiçôes doutrinárias aqui descritas buscam esta sociedade do futuro e estão convencidas de que a mudança é necessária.

Como expóe Edgar Morin em sua obra, é necessário mudar de via, mudar de caminho. A sociedade atual precisa de uma metamorfose, ou seja, sua essência pode ser mantida, mas é necessário que ela seja transformada em algo novo. ${ }^{97}$

É possível compreender uma posição cética do leitor quanto a tudo o que foi até entấo escrito, realmente parece uma utopia inalcançável, algo que ficará apenas nas discussóes catedráticas e em outros fóruns internacionais povoados por apaixonados. No entanto, quando parece ser impossível mudar para um caminho onde não há a supremacia do capital, cabe lembrar as palavras de Morin: "Tudo começa com uma iniciativa, uma inovação, uma nova mensagem de caráter desviante, marginal, com frequência invisivel aos contemporâneos. Foi assim que começaram as grandes religiôes."

\section{Referências}

ALMEIDA, Fernando. O bom negócio da sustentabilidade. Rio de Janeiro: Nova Fronteira, 2002.

ANNAN, Kofi A. "Nós os Povos": O papel das Naçōes Unidas no século XXI. Genebra: Organização das Naçôes Unidas, 2000.

96 BOFF, op. cit., p.53.

97 MORIN, op. cit., p.39.

98 Ibid., p. 39-40. 
BERMEJO, Roberto. La gran transición hacia la sostenibilidad. Madrid: Catarata, 2005.

BOFF, Leonardo. La sostenibilidad: Que es y qué no es. Trad. Jesús García-Abril. Maliaño: Editorial Sal Terrae. 2013.

BOSSELMANN, Klaus. The principle os sustentability: transforming law and governance. Hampshire: Ashgate, 2008.

CARSON, Rachel. Primavera Silenciosa. 1 ed. São Paulo: Gaia, 2010.

COMISSÃO MUNDIAL SOBRE O MEIO AMBIENTE E DESENVOLVIMENTO. Nosso Futuro Comum. 2 ed. Rio de Janeiro: Editora Fundação Getúlio Vargas, 1991.

CONSEJO DE LA TIERRA E INSTITUTO INTERAMERICANO DE COOPERACCIÓN PARA LA AGRICULTURA. La cumbre de la tierra ECO 92: visiones diferentes. São José, CR: IICA, 1993.

DALY, Herman E. Toward some operational principles of sustainable development. Ecological Economics, v.2, p.1-6, 1990.

ELKINGTON, John. Canibais com garfo e faca. São Paulo: Makron Books, 2000.

FERREIRA, Aurélio Buarque de Holanda. Dicionário Aurélio básico da lingua portuguesa. Disponível em http://www.dicionariodoaurelio.com. Acesso em: 17.03.2015.

LAGO, André Aranha Corrêa do. Estocolmo, Rio, Johannesburg: o Brasil e as três conferências ambientais das Naçóes Unidas. Brasília: Instituto Rio Branco, 2006.

McCORMICK, John. Rumo ao paraiso: A história dos movimentos ambientalistas. Rio de Janeiro: Dumará Distribuidora de Publicações, 1992.

MORIN, Edgar. A Via: para o futuro da humanidade. Tradução de Edgard de Assis Carvalho e Mara Perassi Bosco. Rio de Janeiro: Bertrand Brasil, 2013.

OLIVEIRA, José Antônio Pupim de. Empresas na sociedade: sustentabilidade e responsabilidade social. Rio de Janeiro: Elsevier, 2008.

ORGANIZAÇÃO DAS NAÇÓEES UNIDAS. Declaração do Milênio. Cimeira do Milênio. Nova Iorque, 6-8 de setembro de 2000. Lisboa: Centro de Informaçóes das Nações Unidas, 2001.

PROGRAMA DAS NAÇÓES UNIDAS PARA O DESENVOLVIMENTO PNUD. Disponível em: http://www.pnud.org.br/IDH/IDH.aspx?indiceAccordion=0\&li=li_IDH. Acesso em 13.10.2014.

REAL FERRER, Gabriel Real. El Principio de no regresión ambiental a la luz del paradigma de la Sostenibilidad. Material disponível para os alunos do Curso de Doutorado em Ciências Jurídicas da Universidade do Vale do Itajaí em convênio de dupla Titulação com a universidade de Alicante na Espanha. 
REAL FERRER, Gabriel Real. Sostenibilidad, transnacionalidad y trasformaciones del derecho. Material disponível para os alunos do Curso de Doutorado em Ciências Jurídicas da Universidade do Vale do Itajaí em convênio de dupla Titulação com a universidade de Alicante na Espanha.

ROBLEDO, Irene Saavedra (coord.). Introducción a la sostenibilidad y la RSC. La Coruña: Netbiblo, 2010.

SEN, Amartya. Desenvolvimento como liberdade. 1. ed. São Paulo: Companhia de Bolso, 2010.

VEIGA, José Eli da. Desenvolvimento sustentável - O desafio do Sec. XXI. 1a. ed. Rio de Janeiro: Garamond, 2005.

VILCHES, Amparo; MACÍAS, Óscar; PÉREZ, Daniel Gil. La transición a la sostenibilidad: un desafio urgente para la ciência, la educación y la acción ciudadana. Andalucia: Iberciencia. 2014. 